\title{
Perspective on How the FDA Should Review Diagnostic Radiopharmaceuticals
}

\author{
Sally W. Schwarz ${ }^{1}$ and Bonnie Clarke ${ }^{2}$ \\ ${ }^{1}$ Department of Radiology, Washington University School of Medicine, St. Louis, Missouri; and ${ }^{2}$ Research and Discovery Department, \\ Society of Nuclear Medicine and Molecular Imaging, Reston, Virginia
}

\section{See the associated article on page 868.}

$\mathbf{T}$ his article provides readers with some background on concerns raised by Dr. Marcus about the evaluation of radiopharmaceuticals in this issue of The Journal of Nuclear Medicine (1). In 1975, the U.S. Food and Drug Administration (FDA) removed the exemption given to the Atomic Energy Commission for diagnostic radiopharmaceuticals and began regulating these drugs (2). This change was due to the increased use of radiopharmaceuticals and reimbursement by insurance companies and the resulting increased need for controlled production. The approval process of the FDA-whose mission is the safety and efficacy of drugs, including diagnostic drugs - was then applied to radiopharmaceuticals, with filing of an Investigational New Drug (IND) application being required for any new radiopharmaceutical developed (3). The IND primarily includes a chemistry manufacturing and controls section, a toxicology/pharmacology section, and a clinical protocol, including a consent form. Generally, the toxic portion of a drug is the mass present in the formulation, and as Dr. Marcus points out, for radiopharmaceuticals this mass is a very small quantity of the drug (in the range of micrograms to milligrams). In addition, a patient would typically receive only a single injection, again reducing the toxicity issue. For this reason, since the 1990s the nuclear medicine community has worked with the FDA to encourage the reduction of toxicity testing for these diagnostic radiopharmaceuticals.

In 1996 the FDA published a guidance document on single-dose acute toxicity testing for pharmaceuticals (4), followed in 2006 by a guidance document that defined a microdose as less than 1/100th the dose of a test substance calculated (on the basis of animal data) to yield a pharmacologic effect of the test substance with a maximum mass dose of no more than $100 \mu \mathrm{g}$ or, for a protein product, no more than $30 \mathrm{nmol}(5)$. This document reduced the toxicology requirement from the 2 species required for therapeutic drugs to 1 species. The exploratory IND was originally intended for phase $0-1$ studies, but in September 2017, with the issuance of draft guidance on nonclinical microdoses, the FDA expanded the reduced toxicol-

Received Jan. 2, 2018; revision accepted Mar. 22, 2018.

For correspondence or reprints contact: Sally W. Schwarz, Washington University School of Medicine, Department of Radiology, Box 8225, St. Louis, MO 63110.

E-mail: schwarzs@wustl.edu

Published online Mar. 30, 2018.

COPYRIGHT (c) 2018 by the Society of Nuclear Medicine and Molecular Imaging. DOI: 10.2967/jnumed.117.204446 ogy requirements to include traditional IND phase 2-3 studies for diagnostic radiopharmaceuticals (6). Additionally, toxicology studies could be performed not only in good-laboratory-practice laboratories but also in other types of laboratories, such as university comparative anatomy or veterinary medicine departments, further reducing cost.

The field of nuclear medicine expanded from SPECT into PET in the 1990s, and by 1995 the primary PET drug used was ${ }^{18} \mathrm{~F}$ FDG, which was often produced at academic PET centers. The FDA wanted a controlled process for the production of this widely used PET drug and, in 1995, required that PET drugs be regulated under current good manufacturing practices (CGMPs), as had been mandated in 1975 for SPECT drugs. The PET community stepped forward to define the way the CGMPs would be applied to PET, since the mass of drug present in PET drugs is typically in the nanogram-to-milligram range, the half-life of the radionuclides is very short compared with typical SPECT drugs, and the 511-keV energy photon emitted requires significant shielding.

The Food and Drug Modernization Act was signed by President Clinton in 1997. This act constituted the foundation of the FDA regulatory involvement in PET and provided that separate CGMP standards must be written specifically for PET. As a result of this congressional mandate, a radiopharmaceutical committee was formed to work with the FDA, including participation by the Academy of Molecular Imaging, the Society of Nuclear Medicine and Molecular Imaging (SNMMI), and the American College of Nuclear Physicians. In 2003, this interaction between the FDA and the committee resulted in the first 3 FDA approvals of PET radiopharmaceuticalsfor ${ }^{18} \mathrm{~F}$-FDG, ${ }^{18} \mathrm{~F}$-sodium fluoride, and ${ }^{13} \mathrm{~N}$-ammonia.

The FDA met with the nuclear medicine community from 1995 until the final proposed rule on CGMPs for PET drugs was published in 2009. A workshop was convened at the FDA headquarters, and the community was invited to attend. A Coalition for PET Drug Approval was formed in 2010, involving multiple U.S. professional societies and commercial entities in nuclear medicine, including, but not limited to, the SNMMI, the World Molecular Imaging Society, the Society of Molecular Imaging, the National Association of Nuclear Pharmacies, the Society of Radiopharmaceutical Sciences, the American Pharmacists Association, the American Society of Nuclear Cardiology, United Pharmacy Partners, LLC, and the Council on Radionuclides and Radiopharmaceuticals. The FDA coalition meeting was collegial, and significant dialogue ensued, resulting in clarification and changes to the proposed rule; the final rule became effective in title 21 of Code of Federal Regulations, part 212 (21 CFR §212), in 2011 (7).

In 2004 a critical event occurred: hepatitis $C$ contamination of a radiopharmaceutical kit formulation compounded at a centralized nuclear pharmacy (8). This contamination was the result of reusing 
syringes and $0.9 \%$ sodium chloride vials, both of which are singleuse products. It also involved the simultaneous preparation of a kit formulation by the same individual who was radiolabeling white blood cells. Two people died, and 16 people tested positive for hepatitis C RNA; all had received doses from the contaminated radiopharmaceutical vial. Though this was not a toxicity issue per se, an event that causes death will lead to increased scrutiny of a field and to increased FDA oversight in general.

As the field progressed, new drugs were developed, and the microdose exploratory IND was used by commercial groups to screen panels of new drugs with a single toxicity submission. This approach was presented by Avid Radiopharmaceuticals, Inc., at the international conference of the Society of Radiopharmaceutical Sciences in 2009 (9). The FDA has continued to work with the nuclear medicine community to more fully understand the safety of radiopharmaceuticals in light of the limited mass quantities involved. The FDA also understands that the animal models used are often not reflective of human distributions and that singlespecies toxicity studies are aided by initial human studies to gather biodistribution and dosimetry information. The FDA, because of its their mission of safety and efficacy for human use, will likely always require single-species toxicity testing.

Dr. Marcus notes that the cost of getting a radiopharmaceutical approved has increased exponentially since the time of Captain William H. Briner (chairman of the FDA Radiopharmaceutical Advisory Committee in the 1980s). The widely cited study on the cost of developing an imaging drug put the price tag in the $\$ 100$ $\$ 200$ million range, with a timeline of at least 9 y (10). These study data were from 2006, before the requirement that facilities meet CGMP standards. The cost of retrofitting a production facility to meet CGMP requirements averages approximately $\$ 300,000$, and the additional cost of operating a CGMP facility is estimated to be $\$ 10,000$ per year (John Sunderland and David W. Dick, oral/written communication, 2018). These costs do not significantly affect the overall development cost of a drug. Of the recent PET agents approved by the FDA, the $\beta$-amyloid agents are the only ones that went through what is perceived as the typical pathway: discovery, pharmacology/toxicology, first-in-human, phase 2, and phase 3 studies. Anecdotally, it has been reported that development costs for florbetapir and flutemetamol were $\$ 70$ and $\$ 100$ million, respectively. However, not all approved radiopharmaceuticals cost in the tens of millions of dollars to develop. ${ }^{11} \mathrm{C}$-choline injection for PET imaging of patients with suspected prostate cancer recurrence was approved by the FDA in September 2012 at a cost of significantly less than $\$ 70$ million dollars. The safety and effectiveness of ${ }^{11} \mathrm{C}$-choline was documented with a systematic review of 5 published studies involving a total of 98 patients. The FDA noted that there was a substantial body of human studies with ${ }^{11} \mathrm{C}$-choline that showed utility in other cancer types as well. Except for minor skin inflammation at the injection site, no adverse events were reported (11). Of note, this approval occurred after $21 \mathrm{CFR} \S 212$ became effective (7).

This exciting FDA approval of ${ }^{11} \mathrm{C}$-choline helped open the door to approval of 2 additional PET imaging agents: ${ }^{18} \mathrm{~F}$-fluciclovine (Axumin; Blue Earth Diagnostics) and ${ }^{68}$ Ga-DOTATATE (NETSPOT; Advanced Accelerator Applications). ${ }^{18} \mathrm{~F}$-fluciclovine was developed in 1999 by Mark Goodman, $\mathrm{PhD}$, a professor at Emory University School of Medicine. After patenting the radiopharmaceutical, Emory licensed it to Nihon Medi-Physics, which did not develop the PET drug. In 2008 the radiopharmaceutical was relicensed to GE Healthcare, which, in 2014, finally sold the license to the newly formed Blue Earth Diagnostics, a U.K.-based pharmaceutical company. Blue Earth Diagnostics took the radiopharmaceutical forward to the FDA for approval (12). The New Drug Application (NDA) for ${ }^{18} \mathrm{~F}$-fluciclovine was submitted from 4 clinical sites in the United States, Italy, and Norway and analyzed prospectively by Blue Earth Diagnostics. The first study was a comparison of ${ }^{18} \mathrm{~F}$-fluciclovine scans to histopathology data in $105 \mathrm{men}$; the second was a comparison to ${ }^{11} \mathrm{C}$-choline scans in 96 patients. Both studies supported the indication for imaging in prostate cancer patients with elevated prostate-specific antigen levels, and the NDA was approved in May 2016.

One week later, the FDA approved ${ }^{68} \mathrm{Ga}$-DOTATATE for PET imaging to localize somatostatin receptor-positive neuroendocrine tumors in adult and pediatric patients. Three studies established the safety and effectiveness of ${ }^{68} \mathrm{Ga}$-DOTATATE: a comparison to CT or MRI, a comparison to histopathology or clinical follow-up, and an evaluation in patients with neuroendocrine tumor recurrence (13). These studies were based on the vast literature published on somatostatin receptor imaging with ${ }^{68} \mathrm{Ga}$-DOTATATE in Europe over the previous $20 \mathrm{y}$. Neuroendocrine tumors are an orphan disease, which is defined by the FDA as a disease with a prevalence of 200,000 or less. Orphan drugs are handled by the FDA's Office of Orphan Products Development and have a slightly different pathway to approval, including waiving of the \$2.3 million (in 2015) NDA-filing fee mandated by the Prescription Drug User Fee Act. Of note, these 3 most recent drugs took an unorthodox route to FDA approval. Such unique pathways and academic-industrial partnerships may prove to be the future of radiopharmaceutical development.

The FDA recognized that PET drugs were unique because of their short half-lives. When $21 \mathrm{CFR} \S 212$ was introduced (7), the NDA application fees for ${ }^{18} \mathrm{~F}$-FDG, ${ }^{13} \mathrm{~N}$-ammonia, and ${ }^{18} \mathrm{~F}$-sodium fluoride, which were to be submitted in accordance with the PET safety and effectiveness notice (14), were waived. To receive the fee waiver, the applicant had to waive any right to market exclusivity and had to include only indications previously approved by the agency. This fee waiver was consistent with the congressional goal of promoting the availability of FDA-approved PET drugs. Such considerations continue today. Since 2007, PET manufacturers have paid only one sixth of the normal full establishment fee, or about $\$ 85,366$ (2017 rate) for each manufacturing facility. In addition, sites pay a product fee of $\$ 97,750$ (2017 rate) for each approved product. Therefore, a single site making a single drug pays $\$ 183,116$ in fees to the FDA each year (15). On October 1 , 2017 - the effective date of Prescription Drug User Fee Act VI-the establishment-fee special rule for PET drug manufacturing facilities was eliminated. Instead, applicants are assessed an annual prescription drug program fee of $\$ 304,162$ (16). Although this does not represent a decreased fee structure for a single commercial site, it represents a significant decrease for the large centralized nuclear pharmacy networks, such as PETNET Solutions and Cardinal Health. For example, a network of 10 facilities with a single product would have paid over $\$ 850,000$ in establishment fees plus the $\$ 97,750$ product fee; these were replaced by one fee of $\$ 304,162$. These networks allow the availability of these diagnostic drugs throughout the United States.

In her paper, Dr. Marcus also proposes a radiopharmaceutical advisory committee comprising members of the SNMMI and the American College of Nuclear Medicine to review and approve INDs and NDAs for diagnostic radiopharmaceuticals. Although the FDA maintains responsibility for oversight of INDs and NDAs, it does use a group of medical imaging experts as part of its Medical Imaging Drugs Advisory Committee, which "reviews and evaluates data concerning the safety and effectiveness of marketed and investigational 
human drug products for use in diagnostic and therapeutic procedures using radioactive pharmaceuticals and contrast media used in diagnostic radiology and makes appropriate recommendations to the Commissioner of Food and Drugs" (17). The 12-member committee is chaired by Henry Royal, a longtime SNMMI member.

Perhaps the biggest threat to radiopharmaceutical innovation in the United States, especially diagnostics, is the current state of reimbursement. The Centers for Medicare and Medicaid Services, the government payer for the health care of approximately 1 in 3 Americans, had noncoverage language for FDA-approved PET radiopharmaceuticals until March 2013. At that time, the Centers for Medicare and Medicaid Services stated that Medicare coverage for diagnostic PET imaging for oncologic uses may be considered at the discretion of local contractors. Cardiac and neuroimaging indications still receive a noncoverage decision $(18,19)$. If there were dual review and approval by the FDA and the Centers for Medicare and Medicaid Services for diagnostic NDA applications, coverage would be allowed when a radiopharmaceutical is approved. Dual review and approval might also encourage pharmaceutical companies to increase research and development in this important diagnostic area.

${ }^{11} \mathrm{C}$-choline, ${ }^{18} \mathrm{~F}$-fluciclovine, and ${ }^{68} \mathrm{Ga}$-DOTATATE all received favorable coverage decisions from the local Centers for Medicare and Medicaid Services offices, and each was awarded an "A" code for billing purposes. Drugs with pass-through status receive separate reimbursement through the Hospital Outpatient Prospective Payment System for at least $2 \mathrm{y}$, which can be extended to $3 \mathrm{y}$. After the pass-through period expires, the cost of the drug is packaged into the rate of other services performed. For high-cost proprietary drugs, the result is a financial loss for the hospital and, in some cases, limitation of patient access to these important diagnostic agents. Private payers have had mixed coverage of the newer agents, with some radiology benefit managers stating that FDA-approved treatments are investigational, requiring inclusion in National Comprehensive Cancer Network guidelines or published appropriate-use criteria before coverage. An area in which the SNMMI, the World Molecular Imaging Society, and other societies could effect change is the education of radiology benefit managers and private payers on new diagnostics and therapies before their commercialization.

The molecular imaging community has seen a renaissance in recent years, with important new diagnostic agents reaching the clinic, additional radiotherapeutic drugs showing promise (including ${ }^{223} \mathrm{Ra}$-dichloride [Xofigo; Bayer] and most lately ${ }^{177} \mathrm{Lu}-$ DOTATATE [Lutathera; Advanced Accelerator Applications]), and companies new and old entering the space. The SNMMI, the American College of Nuclear Medicine, the World Molecular Imaging Society, and other organizations need to continue their collaboration with one another and with government regulatory agencies to ensure that the promise of personalized radiopharmaceutical medicine is fully realized.

\section{DISCLOSURE}

No potential conflict of interest relevant to this article was reported.

\section{REFERENCES}

1. Marcus CS. How should the FDA review diagnostic radiopharmaceuticals? J Nucl Med. 2018;59:868-870.

2. Radioactive drugs, including biological products. Fed Regist. 1975;40:31314. Codified at 21 CFR $\S 361.1$ ).

3. Title 21: food and drugs - chapter I: Food and Drug Administration Department of Health and Human Services—subchapter D: drugs for human use-part 312: investigational new drug application. U.S. Food and Drug Administration website. https://www.accessdata.fda.gov/scripts/cdrh/cfdocs/cfcfr/cfrsearch.cfm?cfrpart=312. Updated August 14, 2017. Accessed March 27, 2018.

4. Committee for Proprietary Medicinal Products. Position paper on non-clinical safety studies to support clinical trials with a single microdose. Institute of Accelerator Analysis Ltd. website. http://www.iaa-ams.co.jp/img_bsnss/MD1. pdf. Published January 23, 2003. Accessed March 27, 2018.

5. Center for Drug Evaluation and Research. Guidance for industry, investigators, and reviewers: exploratory IND studies. Food and Drug Administration website. http://www.fda.gov/downloads/drugs/guidancecomplianceregulatoryinformation/ guidances/ucm078933.pdf. Published January 2006. Accessed March 27, 2018.

6. Center for Drug Evaluation and Research. Microdose radiopharmaceutical diagnostic drugs: nonclinical study recommendations_-guidance for industry. Food and Drug Administration website. https://www.fda.gov/ucm/groups/fdagov-public/ @fdagov-drugs-gen/documents/document/ucm575453.pdf. Published September 2017. Accessed March 27, 2018.

7. 21 Code of Federal Regulations: part 212 - current good manufacturing practice for positron emission tomography drugs. http://www.gpo.gov/fdsys/pkg/CFR2010-title21-vol4/pdf/CFR-2010-title21-vol4-part212.pdf. Published December 12, 2011. Accessed March 27, 2018.

8. Patel PR, Larson AK, Castel AD, et al. Hepatitis C virus infections from a contaminated radiopharmaceutical used in myocardial perfusion studies. JAMA. 2006;296:2005-2011.

9. Carpenter AP, Pontecorvo MJ, Hefti FF, et al. The use of the exploratory IND in the evaluation and development of ${ }^{18} \mathrm{~F}$-PET radiopharmaceuticals for amyloid imaging in the brain: a review of one company's experience. $Q \mathrm{~J} \mathrm{Nucl} \mathrm{Med} \mathrm{Mol}$ Imaging. 2009;53:387-393.

10. Nunn AD. The cost of developing imaging agents for routine clinical use. Invest Radiol. 2006;41:206-212.

11. FDA approves ${ }^{11} \mathrm{C}$-choline for PET in prostate cancer. $J$ Nucl Med. 2012;53 (12): $11 \mathrm{~N}$

12. FDA approves Emory-developed prostate cancer imaging probe. Emory News Center website. http://news.emory.edu/stories/2016/06/fluciclovine_fda_approval/. Published June 1, 2016. Accessed March 27, 2018.

13. FDA approves new diagnostic imaging agent to detect rare neuroendocrine tumors. U.S. Food and Drug Administration website. https://www.fda.gov/NewsEvents/Newsroom/PressAnnouncements/ucm504524.htm. Published June 1, 2016. Accessed March 27, 2018.

14. Positron emission tomography drug products; safety and effectiveness of certain PET drugs for specific indications. Fed Regist. 2000;65:12999.

15. Prescription drug user fee rates for fiscal year 2017. Federal Register website. https:// www.federalregister.gov/documents/2016/07/28/2016-17870/prescription-drug-userfee-rates-for-fiscal-year-2017. Published July 28, 2016. Accessed March 27, 2018.

16. Prescription drug user fee rates for fiscal year 2018. Federal Register website. https:// www.federalregister.gov/documents/2017/09/14/2017-19494/prescription-drug-userfee-rates-for-fiscal-year-2018. Published September 14, 2017. Accessed March 27, 2018.

17. Medical Imaging Advisory Committee. U.S. Food and Drug Administration website. https://www.fda.gov/AdvisoryCommittees/CommitteesMeetingMaterials/ Drugs/MedicalImagingDrugsAdvisoryCommittee/default.htm. Updated March 21, 2018. Accessed March 27, 2018.

18. Decision memo for positron emission tomography (FDG) for solid tumors (CAG00181R4). Centers for Medicare and Medicaid Services website. https://www.cms. gov/medicare-coverage-database/details/nca-decision-memo. $\operatorname{aspx}$ ?NCAId $=263$. Published June 11, 2013. Accessed March 27, 2018.

19. Decision memo for beta amyloid positron emission tomography in dementia and neurodegenerative disease (CAG-00431N). Centers for Medicare and Medicaid Services website. https://www.cms.gov/medicare-coverage-database/details/ncadecision-memo.aspx ?NCAId $=265$. Published September 27, 2013. Accessed March 27, 2018. 